\title{
Quantification of Adrenergic Nerve Fibers in Human Thymus at Various Ages
}

\author{
D. Cavallottil ${ }^{1}$ M. Artico² and C. Cavallotti \\ ${ }^{1}$ II Neurologic Clinic, ${ }^{2}$ Department of Pharmacology of Natural Substances and General Physiology, Section of Anatomy of the \\ Department of Cardiovascular and Respiratory Sciences University of Rome "La Sapienza" -00161 Rome, Italy \\ (Received 11 April 2000; and accepted 17 May 2000)
}

\begin{abstract}
Adrenergic nerve fibers were studied in human thymus at various ages by biochemical and morphological methods and by quantitative analysis of images. The whole thymus was harvested during autopsies in prenatal of six months $(n=6)$, newborn $(n=6)$, infant $(n=3)$, young $(n=3)$, adult $(n=3)$ and elderly $(n=3)$ men. The thymuses were weighed, dissected and studied. Thymic slices were subjected to specific staining for the detection of microanatomical details regarding thymic microenvironment and nerve fibers. Histofluorescence microscopy was used for staining of adrenergic nerve fibers, while immunofluorescence microscopy was employed for staining of neuropeptide Y-like immunoreactivity. Biochemical dosage of proteins and of noradrenaline amount was performed. All morphological results were subjected to the quantitative analysis of images. Our results confirmed that many changes occur with age in the whole weight of the thymus and in thymic protein content and, as a new finding, demonstrated the specific pattern of three independent markers able to characterize sympathetic nerve fibers of the human thymus and its modifications with age: neuropeptide $\mathrm{Y}$-related staining decreases with age, whereas the density of adrenergic nerve fibers remains unchanged. The apparent discrepancy among these three independent markers for sympathetic nerves was discussed.
\end{abstract}

The intrinsic innervation of the human thymus in prenatal and in postnatal life was studied by Ghali and co-workers (17). In prenatal life, at 11 weeks, nerve fibers invaded the capsule of human thymus and a few trabeculae. At 16 weeks, nerve bundles were accompanied by arteries and veins. During a limited term, from prenatal 28 weeks to postnatal 3 years, did nerve fibers penetrate the parenchyma and encircle or relay with Hassall's corpuscles (19). The thymus vascularization and innervation did not alter up to 9 years, became irregular at 11-13 years and existed up to 15

Correspondence to: Dr Carlo Cavallotti at the above address.

Tel +39-06-4958291 Fax +39-06-4957669

E-mail: cavallotti@uniroma 1.it years. At 25 years nerves were detected only in the capsula and proximal part of the trabeculae. Nerve fibers were located primarily at vascular level, while there was no evidence concerning the innervation of nonvascular thymic tissue (17). Human thymus was also studied for neurofilaments, protein gene product 9.5 (PGP 9.5), tyrosine-hydroxylase, chromogranin A, synaptophysin and pituitary hormones. Adrenergic profile-like immunoreactivity was observed in the medulla. Nerve-like structures were also observed in close relation to the epithelial cells surrounding Hassall's corpuscles (15).

Recently, we studied the GABA-transaminase activity in human thymus (7). Moreover, changes in acetylcholinesterase positive structures were observed in human thymus during the develop- 
ment and age (8). Both of these papers contain further details of the idea that immune system (including the thymus) undergoes a progressive decline in its efficiency with advancing age. In the present paper we have demonstrated the sympathetic innervation of human thymuses at various ages. Until now such studies have been almost entirely confined in the rat (for a review see Cavallotti et al. 9, 10). The sympathetic innervation accounts for a great part of the total innervation of the human thymus. The sympathetic nerve fibers that innervate the human thymus arise from the cervical sympathetic chain. These fibers can be studied by numerous specific staining methods of which we have employed three: 1) histofluorescence microscopy; 2) immunofluorescence microscopy for staining of Neuropeptide Y (NPY)-like immunoreactivity and 3 ) measurement of noradrenaline (NA).

For our experiments, samples of human thymus, obtained from autopsies of male subjects and harvested at various ages were used.

\section{MATERIALS AND METHODS}

In this study the following experimental procedures were performed: 1) harvesting of thymus; 2) cutting of thymus; 3) staining of thymus; 4) staining of nerve fibers; 5) histofluorescence microscopy for the staining of adrenergic nerve fibers (ANF); 6) staining of NPY-like immunoreactivity; 7) measurement of proteins; 8 ) measurement of NA; 9) quantitative analysis of images (Q. A. I); and 10) statistical analysis of data. Each procedure is briefly explained.

1. Harvesting of thymus during autopsies. These experiments were subjected to the approval of the Ethical Committee of our University and, when possible, the close relatives of the deceased gave their informed written consent. During 24 autopsies on 24 subjects (aged between prenatal and 82 years) who died from non-mediastinal and non-neurological diseases and had not been treated with chemo-, radio-, corticosteroid or immunostimulating therapy, the whole thymuses were drawn, cut into small pieces using scissors and weighed. Some pieces were employed for determining biochemical dosages, while others were immediately prefixed by immersion in Bouin's liquid. The thymus, or residual islands of thymic tissue, after involution (in adult or in aged subjects), were found in the retrosternal adipose tissue after the remotion of the sternocostal plate.
Thymuses were rapidly transported to our laboratories for all experimental procedures.

2. Cutting of thymus. Serial sections $(10 \mu \mathrm{m}$ thick) were cut through each piece of the whole thymus on a microtome. Ten consecutive thymic sections were mounted on ten numbered slides (from 1 to 10 ).

The first section was treated with Eosin $\gamma$ to provide histological orientation, to identify the microanatomical details and to define the thymic compartments (28). The second one was treated with Bodian's method to identify the nerve fibers (4). The next three sections (from 3 to 5) were treated for histofluorescence microscopy (24): blank without glyoxylic acid, blank with denatured section, whole reaction. The last five sections (from 6 to 10) were used for immunostaining of NPY (29): four blank plus one section for the whole reaction. Once the serial sections had been cut a small piece of thymus ( $200 \mu \mathrm{m}$ thick) was weighed and, after homogenization, used for the biochemical assays. The same procedure (cut into serial sections) was used for the whole length of the thymus.

3. Staining of thymus. The microanatomical details of thymic tissues were detected with eosinorange (28). After fixation, sections were treated with a working solution of eosin-orange (eosin gamma water soluble $10 \mathrm{~g}$ dissolved in $1,000 \mathrm{~mL}$ of distilled water plus $2 \mathrm{~mL}$ of glacial acetic acid) that represents the stock solution: $25 \mathrm{~mL}$ of stock solution $+75 \mathrm{~mL} \mathrm{H} \mathrm{H}_{2} \mathrm{O}+0.5 \mathrm{~mL}$ of glacial acetic acid constitute the working solution. This staining was considered as "routine" and therefore the results were considered only as control and were omitted from the description of results.

4. Staining of nerve fibers. Nervous structures were coloured by the Bodian's method (4). This method can be used to verify that a stained structure is nervous in nature. In fact, it stains nerve fibers and neurofibrils. After fixation in Bouin's fluid, sections were treated with: 1) 1\% Protargol solution (colloidal silver), 2) reducing solution (Hydroquinone + sodium sulphite), 3) $1 \%$ gold chloride solution, 4) $2 \%$ oxalic acid solution and counterstained with $0.03 \%$ aniline blue. The nerve fibers and neurofibrils are coloured in black. This staining was also considered as a control postcoloration and therefore the results were omitted from the text.

5. Histofluorescence microscopy. For staining of adrenergic nerve fibers (ANF) a glyoxylic acidinduced fluorescence technique was used as de- 
scribed by Qayyum and Fatani (24). Briefly, immediately before use the staining solution was prepared by adding to a solution of $0.236 \mathrm{M}$ potassium phosphate monobasic $(\mathrm{pH} 7.4) 0.2 \mathrm{M}$ sucrose and $1 \%$ glyoxylic acid. This staining is named sucrose, phosphate, glyoxylic acid (SPG). The slides with thymic samples were immediately dipped in this solution for 5 minutes. To assure a comparable fluorescence, it is important to standardize times and temperatures without intervals. After staining, the sections must be drained, covered with non-autofluorescent immersion oil, heated at $95^{\circ} \mathrm{C}$ for $5 \mathrm{~min}$., and coverslipped. The sections must then be immediately observed, analyzed and photographed to prevent the diffusion and the photodecomposition of the fluorescence. The sections were examined and photographed under a Zeiss photomicroscope equipped with exciter and barrier filters and with a mercury lamp for observation of fluorescence.

6. Staining of NPY-like immunoreactivity. The immunohistochemical method proposed by Uddman et al.(29) was used for the detection of NPY positive nerve fibers. Owing to the thickness of the sections $(10 \mu \mathrm{m})$, the samples were incubated for a long time (18-24 h) at room temperature, so that the antibodies completely penetrated the sections, with the rabbit anti-NPY (Cambridge RB-CRB-U. K.) diluted 1:600 in PBS.

Five slides (each containing one slice of sample) were used for each immunostaining experiment. The first four slides were prepared as follows: first blank: primary or secondary antiserum omitted or denatured or previously absorbed with an excess of corresponding peptide; the second blank: primary or secondary antiserum replaced by a non-immune serum; the third blank: sample previously fixed by immersion in a $4 \%$ solution of formaldehyde in PBS that do not preserve the immunoreactive sites; the fourth blank: sample denatured with formaldehyde before or after treatment with primary antiserum or before treatment with secondary antiserum. All these procedures resulted in the absence of any immunoreaction. Positive immunostaining was only observed in the fifth slide that contained the normally treated sample.

After treatment with the specific antibodies (rabbit anti-NPY) the samples were washed in PBS and incubated with fluorescein isothyocyanate-conjugated antiserum (goat antirabbit IgG-Nordic Immunological Reagents: NIR, The Netherlands) diluted 1:100 in PBS for
18-24 hours at room temperature to allow the complete penetration of the fluorescent IgG into the thick sections $(10 \mu \mathrm{m})$. The samples were washed in PBS and observed using a Zeiss III photomicroscope equipped with epi-illumination and Neofluar objectives. Once the nerve fibers have been stained with NPY it is always possible to identify the total fluorescent area of nerve fibers stained by this neurotransmitter under light microscopy. Morphometrical quantification of the NPY-like immunoreactivity was performed using a Quantimet Leica 500 image analyzer (1).

7. Measurement of proteins. In all these experiments, autopsy samples of thymus were weighed and prefixed by immersion in Bouin's fluid (specimens for histochemical staining) or placed into an ice-cold homogenisation buffer (samples for estimating the protein content and the biochemical dosage). Tissue protein concentrations were determined according to the method described by Lowry et al. (23) using bovine serum albumin (BSA) as standard and Folin phenol as reagent.

8. Measurement of Noradrenaline. The NA content of the thymic tissue was determined by HPLC with chromatography at high resolution as reported by Keller et al. (21). Briefly, the tissue samples (weight and protein content of which had previously been determined) were homogenized in a solution 1:10 of perchloric acid $(0.1 \mathrm{~mol} / \mathrm{L})$ with sodium metabisulphite $(0.5 \mathrm{~mol} / \mathrm{L})$ used to prevent the oxidation of NA. The homogenate was centrifuged at $3,000 \mathrm{r} . \mathrm{p}$. m. for $20 \mathrm{~min}$. The supernatant was injected into the chromatographic system in aliquots of 10,20 and $30 \mathrm{~mL}$.

Electrochemical detection was performed using a glassy carbon electrode versus $\mathrm{Ag} / \mathrm{AgCl}$ reference electrode at $0.75 \mathrm{~V}$. The mobile phase was formed by sodium phosphate $(50 \mathrm{mmol} / \mathrm{L})$ citric acid $(25 \mathrm{mmol} / \mathrm{L}) \mathrm{pH} 3.6)$, EDTA $(0.25 \mathrm{mmol} /$ L), octane sulphonic acid (sodium salt 0.75 $\mathrm{mmol} / \mathrm{L}$ ) and $3 \%$ acetonitrile. Results are expressed as $\mathrm{ng} / \mathrm{mg}$ protein $\pm \mathrm{SD}$ :

9. Quantitative analysis of images (QAI). In order to evaluate the amount of staining a quantitative analysis of the intensity of the histofluorescent staining was performed on photographs (to avoid photodecomposition) by means of a Quantimet Analyzer (Leica ${ }^{\square}$ ). The control values, from samples incubated without glyoxylic acid, were considered as "zero". Each photograph was examined separately evaluating the standard error of the mean $(=\mathrm{S}$. E. M.). QAI may provide inaccurate results. In fact, the main choices $(i . e$. 
the instructions for software) are ordered by each research-worker, according to personal preferences. For these reasons the data are more sham than fair and it is necessary to follow very careful rules. The counts must be repeated at least three times using the technique of the double blind. All the counts should be performed by different research-workers, on different analyzers, and with samples identified only by a number or by a letter. Final results must be obtained by another research-worker, who examines experimental protocols to identify each sample and attribute specific values. Final values must be submitted to statistical data analysis. The values reported represent the intensity of staining for each type of treatment and are expressed in conventional units (C. U.) \pm SEM. All these details are reported in the Manual of methods of the Quantimet Leica 500 image analyzer (1).

10. Statistical analysis of data. The statistical methods used throughout this study must be interpreted as an accurate description of the data rather than a statistical inference of such data.

Preliminary studies of each value were performed using basic sample statistics. Mean values, maximum and minimum limits, variations, standard deviation (S. D.), standard error of the mean (S. E. M.) and correlation coefficients were performed according to Serio (25). The relationship between each group of age was studied using the respective correlation coefficients. Finally, a correlative analysis of the morphological and biochemical data was performed. Correlation coefficients denote a significant level less than 0.001 $(P<0.001)$ while the correlation coefficient is not significant when $P>0.05$ (n. s.). This correlation coefficient was calculated according to Castino and Roletto (6).

\section{RESULTS}

Our morphological results are reported in Fig. 14 (staining for NPY-like immunoreactivity) and in Fig. 5-6 (histofluorescence microscopy for the staining of ANF). The result obtained by QAI on occurrence of NPY-like reactive structures in human thymus are reported in tables I-II, while the results on occurrence of ANF in thymic tissues are reported in tables III-IV. Further results on the weight of thymuses protein content and NA amount are reported in tables V and VI.

Fig. 1 deals with the occurrence of NPY-like immunoreactive nerve fibers in thymus of an old man (77 years old). In the subcortical zone, few nerve fibers show a positive reaction. These nerve fibers show an irregular course with varicosities and swellings. In Fig. 2, we observe many thin nerve fibers that run in corticomedullary boundaries. These nerve fibers show an NPY-like positive immunoreaction and posses numerous swellings, beads, crossings and varicosities along their course. This picture represents the thymus of a young man ( 29 years old). Examining the Fig. 3 we can observe that only a little number of NPY-like immunoreactive nerve fibers perforates the capsula (c) of human thymus and penetrates in the subcapsular zone (sz). These fibers are tortuous, tick with beads and varicosities on their course. This figure shows the thymus in an adult man (52 years old). In an infant ( 10 years old) the thymus show numerous NPY-like immunoreactive nerve fibers that run in the cortical area (c)-(Fig. 4). Many neurons (arrows) show a positive reaction. The nerve fibers show spreads of fluorescence on their course due to the technical manipulations and/or to diffusion of the neuropeptide.

In Fig. 5 we can observe the histofluorescence that stains the ANF in the thymus of a young man (22 years old). In the subcapsular zone of the

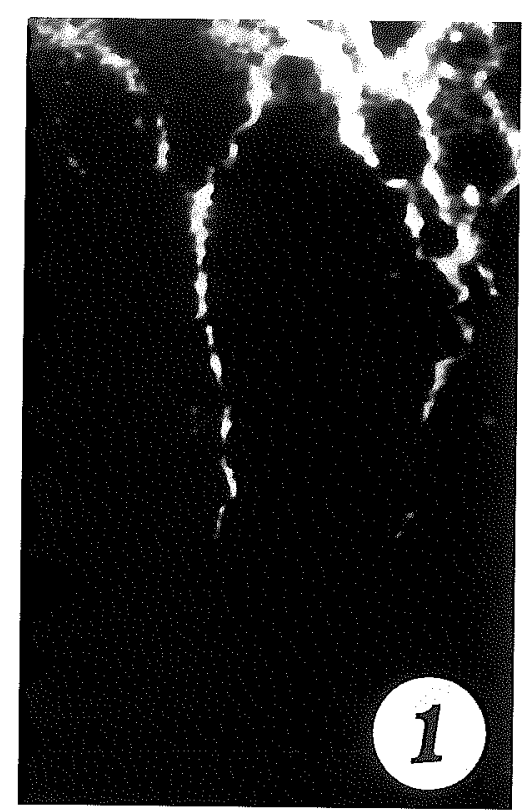

Fig. 1 Human thymus NPY-like positive nerve fibers in an old man (77 years old). Magnification $100 \times$. Many nerve fibers run in the subcortical boundaries. These fibers show an irregular course with varicosities and beads on their course. 


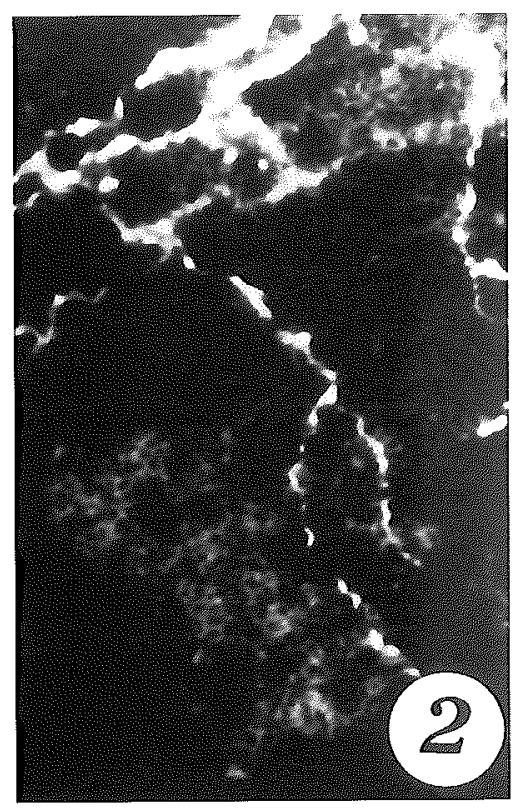

Fig. 2 Human thymus NPY-like positive nerve fibers in an young man (22 years old). Magnification $100 \times$. Many thin nerve fibers run in the corticomedullary zone. These nerve fibers branch out and show swellings, crossings and varicosities along their course.

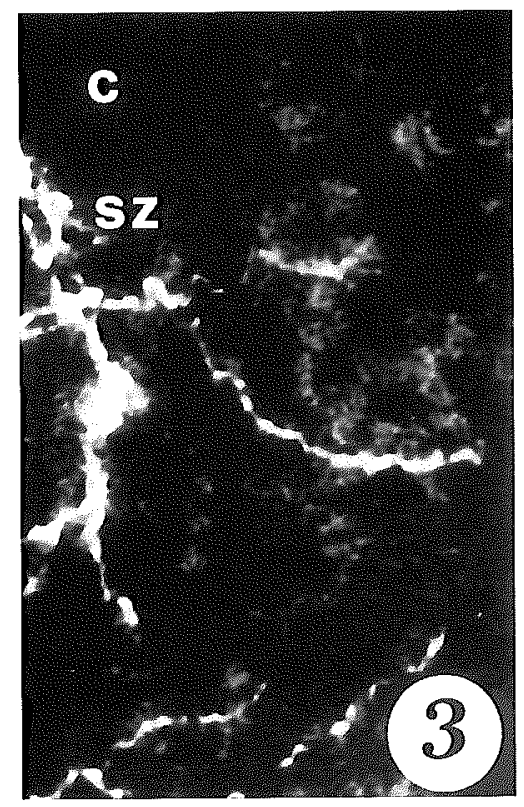

Fig. 3 Human thymus NPY-like positive nerve fibers in an adult man (52 years old). Magnification $100 \times$. Only a small number of nerve fibers perforate the capsula (c) and penetrate into the subcapsular zones (sz). These fibers show thin beads and varicosities.

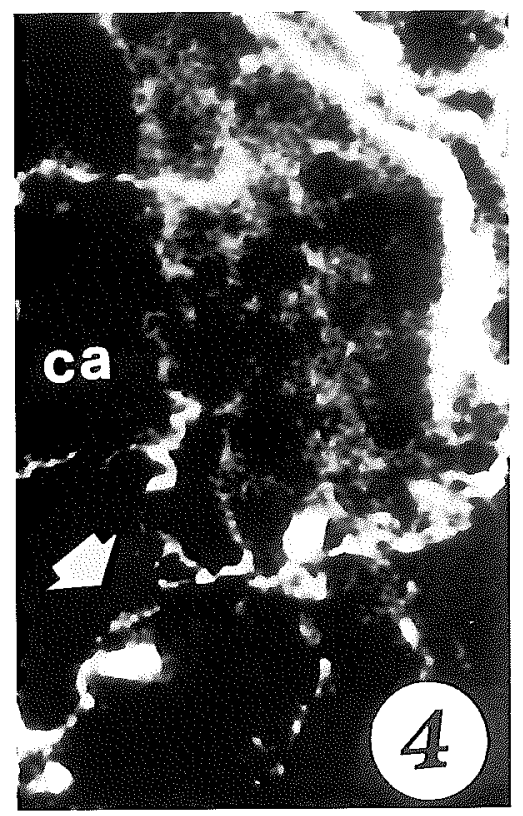

Fig. 4 Human thymus NPY-like positive nerve fibers in an infant male ( 10 years old). Magnification $100 \times$. Many thick nerve fibers run in the cortical areas (ca). Many neurons (arrows) also show a positive reaction. Nerve fibers show thick beads and numerous varicosities along their course. Owing to the technical manipulations we can observe a spread of fluorescence along the course of nerve fibers.

thymus numerous fluorescent nerve fibers form a close mesh network. These nerve fibers show beads, swellings and crossings. Fig. 6 shows the ANF in thymus of an old man ( 77 years old). Numerous fluorescent nerve fibers that run in the corticomedullary zone can be observed. These fibers show beads, swellings and crossings on their course. In spite of aging the ANF remain intact and unchanged. After immunological staining for NPY-like immunoreactivity, the thymic structures of males of various ages (between prenatal and 82 years) were also submitted to QAI. The intensity of staining for NPY was measured in whole fragments of human thymus drawn from autopsies. The number of subjects is indicated as $n=$. The age is reported in Table I for each group. The occurrence of NPY expressed in C. U. \pm SEM is $17.4 \pm 1.3$ in prenatal age, rising to $33.6 \pm 2.7$ in infants and decreasing to $17.8 \pm 1.5$ in elderly males.

Considering the structures of the thymus (Table II) we can see that in the early stages of life $(n=$ 9) the values are higher than that obtained in adult and old men $(n=6)$. A high NPY-like 


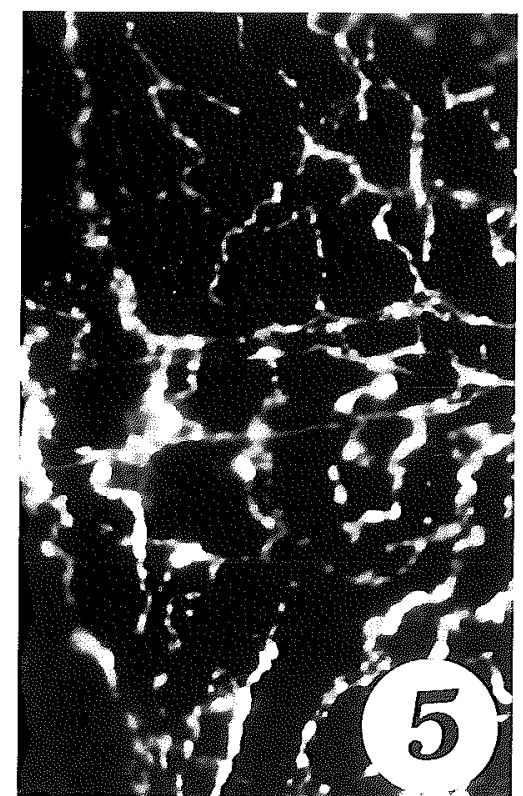

Fig. 5 Human thymus adrenergic nerve fibers in a young man (22 years old). Magnification $200 \times$. In the subcapsular region numerous fluorescent nerve fibers form a rich network. These nerve fibers show beads, swellings and crossings.

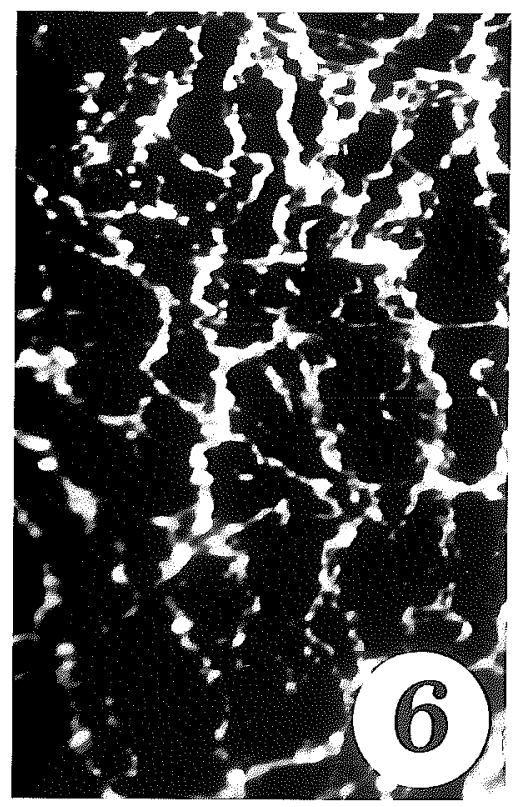

Fig. 6 Human thymus adrenergic nerve fibers in an old man (77 years old). Magnification $200 \times$.Very numerous fluorescent nerve fibers run in the corticomedullary boundaries. These fibers present beads, swellings and crossings on their course.
TABLE I Occurrence of NPY-like fluorescence in thymic structures as revealed by QAI performed after immunological staining during development and aging.

\begin{tabular}{|c|c|c|}
\hline Age group & & $\begin{array}{l}\text { NPY } \\
\text { C.Us. } \pm \text { SEM }\end{array}$ \\
\hline $\begin{array}{l}\text { Prenatal } 6 \text { month } \\
n=6\end{array}$ & & $17.4 \pm 1.3$ \\
\hline $\begin{array}{l}\text { Newborn } \\
n=6\end{array}$ & & $34.2 \pm 2.6^{*}$ \\
\hline $\begin{array}{l}8-12 \text { years } \\
n=3\end{array}$ & Infant & $35.6 \pm 2.7^{\text {n.s. }}$ \\
\hline $\begin{array}{l}22-24 \text { years } \\
n=3\end{array}$ & Young & $28.2 \pm 2.2 *$ \\
\hline $\begin{array}{l}50-62 \text { years } \\
n=3\end{array}$ & Adult & $20.1 \pm 1.7^{*}$ \\
\hline $\begin{array}{l}77-82 \text { years } \\
n=3\end{array}$ & Old & $17.8 \pm 1.5^{*}$ \\
\hline $\begin{array}{l}0-82 \text { years } \\
n=24\end{array}$ & Total & $25.1 \pm 1.9$ \\
\hline
\end{tabular}

The intensity of staining for NPY was measured in whole fragments of human thymus drawn from autopsies. The number of subjects $(n=)$ is indicated for each group of age. All the values \pm SEM were obtained using a Quantimet (Leica $\left.{ }^{\circledR}\right)$ and are expressed as Conventional Units (C. Us) see methods. ${ }^{*} P<0.001 ;$ n. s. $=$ not significant; $P$ was calculated comparing results in old versus adult animals and so on.

immunoreactivity is localized in structures resembling nerve fibers and in the subcapsular zone both in young than in adult and in old subjects. In old subjects NPY-like immunoreactivity is decreased in the thymic microenvironment while it is increased around Hassall's corpuscles (considered to be a marker of thymic involution). Table III summarizes the occurrence of ANF in thymic tissues as revealed by QAI performed after histofluorescent staining at various ages. The results are expressed as C. U. \pm SEM. We can observe that the pattern of ANF is different from the pattern of NPY-like immunoreactivity (Table II). In fact, the ANF (Table III) are highest in prenatal thymuses, and they increase in amount from prenatal life to twelve years of age. After this age the ANF decrease $(29.1 \pm 3.1$ C. U. in adult), 
TABLE II Occurrence of NPY-like fluorescence in thymic structures as revealed by QAI performed after immunological staining in thymus of two classes of age.

\begin{tabular}{l|c|c}
\hline Structures of Thymus & $\begin{array}{c}\text { Subjects } \\
\text { 1st stages of life } \\
\mathrm{N}=9\end{array}$ & $\begin{array}{c}\text { Subject } \\
\text { Last stages of } \\
\text { life } \mathrm{n}=6\end{array}$ \\
\hline 1) Whole Thymus & $43.8 \pm 2.5$ & $22.5 \pm 1.8^{*}$ \\
\hline $\begin{array}{l}\text { 2) Thymic } \\
\text { microenvironment }\end{array}$ & $66.5 \pm 3.7$ & $36.4 \pm 2.4^{*}$ \\
\hline $\begin{array}{l}\text { 3) Structures resembling } \\
\text { nerve fibers }\end{array}$ & $63.8 \pm 3.4$ & $56.7 \pm 3.9^{*}$ \\
\hline 4) Reticular cells & $28.7 \pm 2.1$ & $19.6 \pm 1.7^{*}$ \\
\hline 5) Lymphocytes & $24.3 \pm 1.9$ & $12.1 \pm 1.4^{*}$ \\
\hline 6) Corpuscle of Hassall & $40.1 \pm 2.7$ & $44.7 \pm 3.3^{*}$ \\
\hline 7) Arterioles & $39.5 \pm 2.7$ & $38.2 \pm 2.5^{\text {n.s. }}$ \\
\hline 8) Venules & $28.3 \pm 2.1$ & $25.3 \pm 1.9^{\text {n.s. }}$ \\
\hline 9) Lymphatic vessels & $11.4 \pm 0.9$ & $11.8 \pm 0.8^{\text {n.s. }}$ \\
\hline 10) Septa & $9.3 \pm 0.7$ & $9.1 \pm 0.6^{\text {n.s. }}$ \\
\hline 11) Capsula & $8.1 \pm 0.5$ & $8.6 \pm 0.5^{\text {n.s. }}$ \\
\hline
\end{tabular}

The intensity of staining for NPY was measured in thymus of nine subjects of two classes of age $(n=9)$. On the basis of microanatomical details revealed by staining with Eosin-Orange we can distinguish all the structures pointed out with numbers $1-11$. The parenchyma of thymus is called also the thymic microenvironment and particularly includes the structures pointed out with numbers 4-7. All the values \pm SEM arise from Quantimet (Leica ${ }^{\otimes}$ ) and are expressed as Conventional Units (C. Us.) see methods. ${ }^{*} P<0.001 ; \mathrm{n} . \mathrm{s} .=$ not significant; $P$ was calculated comparing results in old versus young animals and so on.

but remain unchanged in old men $(28.7 \pm 1.9 \mathrm{C}$. U.). If we consider the single structures of the thymus (Table IV) the pattern of ANF observed is different from that of NPY-like immunoreactivity (Table II). In fact, ANF are higher at an early age than later in life. Moreover, the ANF are localized particularly in the thymic microenvironment and around the corpuscles of Hassall. They increase during development and remain unchanged with age. A lower decrease can be observed in the thymic microenvinronment while around the corpuscles of Hassall the occurrence of ANF appears unvaried or increased. As mentioned, the corpuscles of Hassall are considered to be an expression of thymic involution.

Table $V$ shows the weight of thymus (expressed in $\mathrm{g} \pm \mathrm{SD}$ ) and its protein content (expressed in $\mathrm{mg} / \mathrm{g}$ fresh weight $\pm \mathrm{SD}$ ) in subjects of various ages (between prenatal and 82 years of age). As can be seen, the weight of the thymus increases between prenatal age and 12 years of age. After this age, the weight of the thymus decreases to $5.57 \pm 0.44 \mathrm{~g}$ in elderly men (77-82 years old). The amount of proteins in the thymus is in accordance with the values of thymus weight. The values of proteins increases from prenatal to 12 years of age (from $20.8 \pm 1.6$ to $36.3 \pm 2.1 \mathrm{mg} / \mathrm{g}$ fresh weight). After this age, protein values rapidly decrease passing to $18.2 \pm 1.9$ in young men, $10.8 \pm 0.8$ in adults and $7.1 \pm 0.5 \mathrm{mg} / \mathrm{g}$ fresh weight in old men. The biochemical values of NA in the supernatant of human thymus at various ages are reported in Table VI. As can be seen, in prenatal life the NA amount is $38.3 \pm 7.6 \mathrm{ng} / \mathrm{mg}$ of protein. It increases to $136.6 \pm 13.8 \mathrm{ng} / \mathrm{mg}$ of protein in infant $(<12$ years old). After this age there is a strong increase 
TABLE III Occurrence of ANF in thymic tissues as revealed by $Q A I$ performed after histofluorescence microscopy during development and aging.

\begin{tabular}{|c|c|}
\hline Age group & $\begin{array}{c}\text { ANF } \\
\text { C. Us. } \pm \text { SEM }\end{array}$ \\
\hline $\begin{array}{l}\text { Prenatal } 6 \text { month } \\
\mathrm{n}=6\end{array}$ & $37.4 \pm 3.9$ \\
\hline $\begin{array}{l}\text { Newborn } \\
\mathrm{n}=6\end{array}$ & $56.2 \pm 6.4^{*}$ \\
\hline $\begin{array}{l}8-12 \text { years } \\
n=3\end{array}$ & $58.4 \pm 7.1^{\text {n.s. }}$ \\
\hline $\begin{array}{l}22-24 \text { years } \\
n=3\end{array}$ & $47.9 \pm 5.3^{*}$ \\
\hline $\begin{array}{l}50-62 \text { years } \\
n=3\end{array}$ & $29.1 \pm 3.1 *$ \\
\hline $\begin{array}{l}77-82 \text { years } \\
n=3\end{array}$ & $28.7 \pm 1.9^{\text {n.s. }}$ \\
\hline $\begin{array}{l}0-82 \text { years } \\
n=24\end{array}$ & $41.3 \pm 4.2$ \\
\hline
\end{tabular}

The intensity of staining for ANF was measured in whole fragments of human thymus drawn from autopsies. The number of subjects $(n=)$ is indicated for each group of age. All the values \pm SEM arise from Quantimet (Leica ${ }^{\mathbb{Q}}$ ) and are expressed as Conventional Units (C. Us) see methods. ${ }^{*} P<0.001$; n. s. $=$ not significant; $P$ was calculated comparing results in old versus adult animals and so on.

of the NA amount. In fact the $\mathrm{Na}$ amount is $184.4 \pm 11.5$ in young, $553.7 \pm 10.2$ in adult and $468.5 \pm 8.8 \mathrm{ng} / \mathrm{mg}$ of protein $\pm \mathrm{SD}$ in old men. In conclusion, five series of data were considered: (1) immunocytochemistry for NPY, (2) histofluorescence for ANF, (3) biochemical determination of NA, (4) whole weight of thymus, and (5) protein content of thymus) in six age-groups (prenatal, newborn, infant, young, adult and old).

For assessment of developmental changes, we must consider the first three age-groups (prenatal, newborn and infant) while for age-related changes the last three ages (young, adult, old) must be taken into account. Although NPY staining appears to decrease with age, NA content increases and ANF density remains unchanged. Thymus weight decreases with age and at the same time the protein content of thymus also decreases with age.

\section{DISCUSSION}

Three independent markers for characterizing sympathetic nerves of human thymus and its age-related changes were studied. However, interpretation of the mismatch or contrasting results provided by these three markers is a matter of debate. In fact, NPY staining decreases with age while NA content increases. The apparent contradiction of both these results is due to the solubility of NA. This neurotransmitter is linked to the proteins of low molecular weight that pass through the supernatant after centrifugation of the whole homogenate. The soluble proteins increase with age and therefore NA (linked to the soluble proteins) also increases with age. ANF density does not appear to be modified with age and with thymic involution. In fact, ANF retain their characteristics even if there is a marked reduction in the thymic microenvironment.

Identification of NPY in peripheral tissues such as the thymus requires extreme care. Immunohistochemical techniques are able to show in situ the localization of numerous neuropeptides including NPY; immunohistochemistry uses fluorescent antibodies to stain neuropeptides in specific structures on tissue sections. Fluorescein isothiocyanate is a common fluorescent marker used to visualize the immunohistochemical reaction. Because of the potential for antibody cross-reactivity to chemically related antigens, together with other non-specific antigens, immunohistochemical staining is never unequivocal and absolute. The specific staining of a neuropeptide requires numerous controls. Even after all the controls have been performed, absolute identification of a specific neuropeptide still requires a biochemical analysis. For these reasons, in all immunohistochemical results the descriptive suffix "NPY-like immunoreactivity" must be used (12-14). In one of our recent publications (11) regarding changes in parasympathetic nerve fibers in the human thymus after an immuneresponse, we demonstrated that there is direct evidence of a specific localization of acetylcholinesterase (AChE) activity in the human thymus. In fact, structures resembling nerve fibers and/or lymphatic tissue of the human thymic gland show a positive $\mathrm{AChE}$ staining. Moreover, lymphatic vessels, reticular cells and epithelial cells of the human thymus show a specific localization of $\mathrm{AChE}$ that may act on some thymic parasympathetic receptors stimulating the 
TABLE IV Occurrence of ANF in thymic tissues as revealed by $Q A I$ performed after histofluorescence microscopy in two age groups.

\begin{tabular}{l|c|c}
\hline Structures of Thymus & $\begin{array}{c}\text { Subjects } \\
\text { 1st stages of life } \\
\mathrm{n}=9\end{array}$ & $\begin{array}{c}\text { Subjects } \\
\text { Last stages of } \\
\text { life } \mathrm{n}=6\end{array}$ \\
\hline 1) Whole Thymus & $57.3=7.4$ & $29.8 \pm 3.2^{*}$ \\
\hline $\begin{array}{l}\text { 2) Thymic } \\
\text { microenvironment }\end{array}$ & $71.4 \pm 8.3$ & $58.5 \pm 4.1^{*}$ \\
\hline $\begin{array}{l}\text { 3) Structures resembling } \\
\text { nerve fibers }\end{array}$ & $88.6 \pm 8.7$ & $79.8 \pm 7.4^{*}$ \\
\hline 4) Reticular cells & $45.1 \pm 4.1$ & $21.7 \pm 2.3^{*}$ \\
\hline 5) Lymphocytes & $36.1 \pm 3.3$ & $18.4 \pm 1.9^{*}$ \\
\hline 6) Corpuscle of Hassall & $61.4 \pm 6.2$ & $66.3 \pm 6.4^{*}$ \\
\hline 7) Arterioles & $50.4 \pm 5.4$ & $33.2 \pm 3.1^{*}$ \\
\hline 8) Venules & $41.3 \pm 4.3$ & $28.5 \pm 2.9^{*}$ \\
\hline 9) Lymphatic vessels & $31.3 \pm 3.3$ & $19.8 \pm 2.1^{*}$ \\
\hline 10) Septa & $10.4 \pm 1.2$ & $10.1 \pm 1.3^{\text {n.s. }}$ \\
\hline 11) Capsula & $9.1 \pm 0.9$ & $9.4 \pm 1.1^{\text {n.s. }}$ \\
\hline
\end{tabular}

The intensity of staining for ANF was measured in thymus of nine subjects of two classes of age $(n=9)$. On the basis of microanatomical details revealed by staining with Eosin-Orange we can distinguish all the structures pointed out with numbers 1-11. The parenchyma of thymus is called also the thymic microenvironment and it includes expecially the structures pointed out with numbers 4-7. All the values \pm SEM arise from Quantimet (Leica ${ }^{\circledR}$ ) and are expressed as Conventional Units (C.Us.) see methods. ${ }^{*} P<0.001 ;$ n. s. $=$ not significant; $P$ was calculated comparing results in old versus young animals.

thymosin levels in man too. The progressive involution of the human thymus with age has been well documented by Simpson and coworkers (26) and by Singh and Singh (27) and is accompanied by a decline of its neuroendocrine activities $(18,22)$. These changes characterize the morphological aspects of immune senescence (30). In fact, one of the most important findings documented in this paper is the decrease of NPY-immunoreactive nerve fibers in human thymus with age. These nerve fibers exert vasomotor effects on the vasculature (16). The decrease of NPY-immunoreactive nerve fibers is correlated to the thymic involution and to the decrease of thymic vasculature. The pattern of ANF remains unchanged with thymic involution, maintaining its characteristics even when there is a marked involution of the thymic microenviron- ment $(2,5,20)$.

The disagreement between NPY-immunoreactive nerve fibers and ANF may be explained by considering that both are sympathetic nerve fibers (SNF) and ANF consist of only a small part of the whole SNF number. The levels of thymic NA are also increased because it is linked to the soluble proteins that are increased with age.

In conclusion, three independent markers for sympathetic nerves of human thymus at various ages are reciprocally in mismatch. However, in order to interpret or to reconcile these apparent discrepancies we can take into account the different pattern, the different binding and the different physical-chemical states of these three neurotransmitters (adrenaline, noradrenaline and NPY). Moreover, we can hypothesize that all three of these sympathetic neurotransmitters may be 
TABLE V Weight of the thymus and protein content in thymic tissue homogenates during development and aging.

\begin{tabular}{lr|c|c}
\hline Age group & \multicolumn{1}{c|}{$\begin{array}{c}\text { Weight of thymus } \\
\text { gr } \pm \text { SD }\end{array}$} & $\begin{array}{c}\text { Protein } \\
\text { mg/gr fresh } \\
\text { weight } \pm S D\end{array}$ \\
\hline $\begin{array}{l}\text { Prenatal } 6 \text { month } \\
\mathrm{n}=6\end{array}$ & $12.03 \pm 1.65$ & $20.8 \pm 1.6$ \\
\hline $\begin{array}{l}\text { Newborn } \\
\mathrm{n}=6\end{array}$ & $18.06 \pm 2.16^{*}$ & $31.5 \pm 2.4^{*}$ \\
$\begin{array}{l}8-12 \text { years } \\
\mathrm{n}=3\end{array}$ & Infant & $30.56 \pm 3.36^{*}$ & $36.3 \pm 2.1^{*}$ \\
$\begin{array}{l}22-24 \text { years } \\
\mathrm{n}=3\end{array}$ & Young & $21.24 \pm 2.44^{*}$ & $18.2 \pm 1.9^{*}$ \\
\hline $\begin{array}{l}50-62 \text { years } \\
\mathrm{n}=3\end{array}$ & Adult & $10.12 \pm 1.39^{*}$ & $10.8 \pm 0.8^{*}$ \\
\hline $\begin{array}{l}77-82 \text { years } \\
\mathrm{n}=3\end{array}$ & Old & $5.57 \pm 0.44^{*}$ & $7.1 \pm 0.5^{*}$ \\
\hline $\begin{array}{l}0-82 \text { years } \\
\mathrm{n}=24\end{array}$ & Total & $16.61 \pm 2.18$ & $19.3 \pm 1.5$ \\
\hline
\end{tabular}

Results of weight of thymus are expressed in $g$ while protein content is expressed in $\mathrm{mg} / \mathrm{g}$ weight fresh tissue. Each value is the mean $\pm \mathrm{SD}$ of single determinations from each of the number of subjects reported as n. ${ }^{*} P<0.001$. $P$ was calculated comparing results in old versus adult animals and so on.

TABLE VI Biochemical values of NA in the supernatant of human thymus at various ages.

\begin{tabular}{lr|c}
\hline Age group & \multicolumn{1}{|c}{$\begin{array}{c}\text { NA } n g / m g \\
\text { protein } \pm S D\end{array}$} \\
\hline Prenatal 6 month $(n=6)$ & $38.3 \pm 7.6$ \\
\hline Newborn $(n=6)$ & & $130.1 \pm 13.4^{*}$ \\
\hline $8-12$ years $(n=3)$ & Infant & $136.6 \pm 13.8^{\text {n.s. }}$ \\
\hline $22-24$ years $(n=3)$ & Young & $184.4 \pm 11.5$ \\
\hline $50-62$ years $(n=3)$ & Adult & $353.7 \pm 10.2^{*}$ \\
\hline $77-82$ years $(n=3)$ & Old & $468.5 \pm 8.8^{*}$ \\
\hline $0-82$ years $(n=24)$ & Total & $281.5 \pm 11.7$ \\
\hline
\end{tabular}

Each value expressed as $\mathrm{ng} / \mathrm{mg}$ protein $\pm \mathrm{SD}$ is the mean of three independent determination from the number of subjects indicated $(n=)$. Supernatant is a fraction of thymus (see methods).

${ }^{*} P<0.001 ; \mathrm{n}$. s. $=$ not significant; $P$ was calculated comparing results in old versus adult animals and so on. related to the specific functions of the thymocytes and of the reticular cells, as previously suggested by Bellinger et al.(3).

\section{Acknowledgments}

The present study was supported by grants from University of Rome "La Sapienza" and MURST. The Authors are greatly indebted to Drs. V. Diaczencko and V. Bilotta for their suggestions and criticisms. The technical assistance of $\mathrm{Mr}$. Dario Caporuscio, the excellent secretarial work of Mrs. Silvana Casamento, the photographic service of Mr. Giuseppe Leoncini, and the kind help of Mrs. Sharon Hobby in the revision of the English language are also gratefully acknowledged. 


\section{REFERENCES}

1. Adobe A., (1997) Manual of Methods of Quantimet 500 Leica Microsystems Imaging Solution Ltd. Leica, Clifton Road, Cambridge, U. K.

2. Bach M. A., Beaurain G. J. (1979) Respective influence of extrinsic and intrinsic factors on the age-related decrease of thymic secretion. Immunology 112, 2505-2512.

3. Bellinger D. L., D. Lorton, S. Y. Felten, Felten D. L. (1992) Innervation of lymphoid organs and implications in development, aging and autoimmunity. Int. J. Immunopharmacol. 3, 329-344.

4. Bodian D., (1936) A new method for staining nerve fibers and nerve endings in mounted paraffin sections. Anat. Rec, 65, 89-97.

5. Bullock K., (1985) Neuroanatomy of lymphoid tissue: a review. In Guillemin, R. (ed.) Neural modulation of Irnmunity, New York, Raven Press, pp. 111-141.

6. Castino M., Roletto E. (1992) Statistica Applicata. Piccin, Padua.

7. Cavallotti C., Artico M., De Santis S. (1999) Occurrence of GABA-transaminase in the thymus gland of juvenile and aged rats. Eur. J. Histochem 43, 293-299.

8. Cavallotti D., Artico M., Iannetti G., Cavallotti C. (2000) Quantification of acetylcholinesterase-positive structures in human thymus during development and aging. Neurochemi. Internat. 36, 75-82.

9. Cavallotti C., Artico M., Cavallotti D. (1999) Occurrence of adrenergic nerve fibers and of noradrenaline in thymus gland of juvenile and aged rats. Inmmunol. Letters 70, 5362.

10. Cavallotti C., Artico M., De Santis S., Tranquilli Leali F. M. (1999) Distribution of acetylcholinesterase activity in thymus of juvenile and aged rats. Biomed. Res. 20, 73-80.

11. Cavallotti D., Artico M., Cavallotti C. (1999) Acetylcholinesterase activity in the human thymus during immuneresponse. Biomed. Res. 20, 42-52.

12. Coons A. H., Greech V. J., Jones R. N. (1941) Immunological properties of an antibody containing a fluorescent group. Proc. Soc. Exp. Biol. 47, 200-212.

13. Coons A. H., Kaplan M. H. (1950) Localization of antigens in tissue cells. II Improvement in a method for the detection of antigen by means of fluorescent antibody. $J$ Exp. Med. 91, 1-10.

14. Coons A. H., Leduc E. H., Connoly ]. M. (1960) Studies on antibody production I. A method for the histochemical demonstratlon of specific antibody and its application to a study of the hyperimmun rabbit. J. Exp. Med. 102, 4960.

15. de Leeuw E. E., Jansen G. H., Batanero E., van Wichen D.
F, Huber J., Schounman H. J. (1992) The neural and neuroendocrine component of the human thymus. I. Nerve-like structures. Brain Behav Immun 6, 234-248.

16. Fabris N., Pierpaoli W., Sorkin E. (1972) Lymphocytes, hormones and aging. Nature 240, 557-559.

17. Ghali W. M., Abdel-Rahman S., Nagib S., Mahran Z. Y. (1980) Intrinsic innervation and vasculature of pre- and post- natal human thymus. Acta Anatomica 108, 115-123.

18. Goldestein A. L, Low T. L. K., Thurman G. B., Zatz N. M, Hall N.R., Chen C. P., Ku S. L., Naylor P. H., McClure J. E. (1981) Current status on thymosin and other hormones of the thymus gland. Rec Progr Horm Res 37, $369-415$.

19. Haar J. L., (1974) Light and electron microscopy of the human fetal thymus. Anat Rec 179, 463-476.

20. Hadden J. W., Galy A., Chen H., Wang Y., Hadden E. (1989) The hormonal regulation of thymus and $T$ lymphocytes development and function. In Hadden J. W., Masek K., Nistico G. (eds.): Interactions among CNS, Neuroendocrine and Immune Systems, pp. 148-164, Rome, Pythagora Press.

21. Keller R., Oke A., Meflord I., Adams R. N. (1976) Liquid chromatographic analysis of catecholarnines Life Sci 19 , 995-1004.

22. Levis V. M., Twomey J. J., Bealmear P., Goldstein G., Good R. A. (1978) Age, thymic involution and circulating thymic hormone activity. Clin. Endocrinol. Metab. 47, $145-150$.

23. Lowry O. H., Rosebrough N. J., Farr A. L., Randall R. J. (1951) Protein measurement with the Folin phenol reagent. J. Biol. Chem. 193, 265-275.

24. Qayyum M. A., Fatani J. A. (1985) Use of glyoxilic acid in the demonstration of autonomic nerve profiles. Experientia 41, 1389-1390.

25. Serio A., (1986) Appunti dalle lezioni di statistica sanitaria, Kappa ed., Rome.

26. Simpson J. G., Gray E. S., Beck J. S. (1975) Age involution in the normal human adult thymus. Clin. Exp. Immunol. 19, 261-267.

27. Singh J., Singh A. K. (1979) Age-related changes in human thymus. Clin. Exp. Immunol. 37, 507-514.

28. Townsend F. M. (1960) Manual of Histologic and Special Staining Techniques. New York, Mc Graw-Hill.

29. Uddmann R., Ekblad E., Edvinsson L., Hakanson R., Sundler F. (1985) Neuropeptide Y-like immunoreactivity in perivascular nerve fibers of the Guinea pig. Regul. Pep. 10, 243-256

30. Weksler M. E., Siskind G. W. (1984) The cellular basis of immune senescence. Monogr. Dev. Biol. 17, 110-121. 